\title{
Implant Supported Mandible Over Denture with Four Implants Key Facts
}

Farhan Durrani

\begin{abstract}
Implant retained over denture (IRO) is a satisfactory treatment modality for edentulous patient with problems with their lower denture. There are good reasons why this treatment should be selected in preferences to using tissue supported dentures. There are certain rules that provide a method to control the mechanical environment, addressing factors effecting implant and prosthesis longevity, including magnitude of forces, resistance of prosthesis against theses forces, and the biology of bone and its ability to respond to loading environments.
\end{abstract}

Materials and methods: Ten edentulous patients were selected for implant retained prosthesis for the mandible, with minimum four implants in parasymphysis region and prosthesis were delivered after period of 3 months.

Conclusion: Certain important points needs consideration for successful prosthesis and its longevity.

Keywords: Implant, Overdenture, Mandible, Planning, Edentulism.

Key message: The report provides simple rules for treatment planning in implant therapy in edentulous mandible with minimum of four implants that both acknowledge and control the mechanical environment. This influences the success of both the end osseous dental implants and the prosthesis and can offer lasting success for treatment of edentulous mandible.

How to cite this article: Farhan Durrani. Implant Supported Mandible Over Denture with Four Implants Key Facts. Int J Oral Implantol Clin Res 2013;4(3):99-101.

Source of support: Nil

Conflict of interest: None declared

\section{INTRODUCTION}

Approximately 17 years ago Steenberghe ${ }^{1}$ proposed possibility of using over denture supported by two Branemark implants to treat mandible denture problems with $98 \%$ success rate, he further elaborated of placing fewer implants in advantageous sites rather than placing as many implants in limited space to completely rehabilitate an edentulous ridge for fixed or over denture prosthesis .The contemporary literature demonstrates high degree of survival over 10 to 20 years time horizon when implants are placed in the parasymphyseal mandible and restored with implant retained over denture or implant retained fixed prosthesis. ${ }^{2-5}$ These studies invoke inclusion and exclusion criteria that favor success, benefit from local factors of mandible bone quality and quantity, and commonly employ the use of opposing maxillary denture. In order to provide a conceptual framework to manage treatment of edentulism using dental implants, three rules for treatment planning affecting implant and prosthesis longevity have been addressed which provide rationale to support general rules and illustrate their application in treatment planning.

\section{MATERIALS AND METHODS}

Ten complete edentulous patients were selected with average resorption of mandible (bone available in parasymphysis region $>10 \mathrm{~mm}$ ). Four implants with average length of $10 \mathrm{~mm}$ with width $>3.5 \mathrm{~mm}$ were placed with prescribed surgical protocols. The prosthesis was based upon fabrication techniques utilizing methyl methacrylate and cross linked denture teeth. The materials provide functional substrate and esthetic foundation of implant based prosthesis. Patients criterias were (1) sufficient bone volume for implants with a length of $10 \mathrm{~mm}$ and a acceptable diameter $>3.5 \mathrm{~mm}$ with one millimeter bone available around the crestal part of implants, (2) healed extraction sites (6 weeks or longer), and (3) satisfying dentures with respect to occlusion, esthetics, vertical dimension in occlusion, denture base extension and fit. The rejecting criterias included: (1) heavy smokers (>20 cigarettes per day), (2) need of bone augmentation, (3) a history of radiotherapy in the interforamina region, (4) systemic diseases precluding implant surgery.

\section{DISCUSSION}

There are certain rules which were followed in each of the patient; these points can be taken as important facts necessary for the implant supported denture fabrication in mandibular edentulism.

\section{Fact 1}

Inferior/superior dimension of the mandible must be $\geq 10 \mathrm{~mm}$ (Fig. 1).

This rule states that minimum alveolar dimension sufficient to support an implant retained prosthesis must be equal or greater than $10 \mathrm{~mm}$.

The use of $10 \mathrm{~mm}$ or less in length in implant retained prosthesis is well-defined and successful. ${ }^{6}$ Majority of cases implant failures occurred before loading. The evaluation of 119 patients rehabilitated with four implants to support mandibular fixed prosthesis revealed $99.1 \%$ success rate. ${ }^{7}$ A 3-dimensional element model demonstrated that implant 
length had no appreciable effect on stress distribution at the bone/implant interfaces when loaded by a cantilever prosthesis, suggesting that implant length does not dictate survival. ${ }^{8}$ A high survival rate $(95.5 \%)$ with 20 years of loading. Although $21 \%$ of implants were $8.5 \mathrm{~mm}$ or shorter, implant length and bone quality did not affect implant survival. ${ }^{9}$ This concludes that implants of around $10 \mathrm{~mm}$ have equally high survival in the parasymphyseal region of mandible for IRO and increasing implant length beyond $10 \mathrm{~mm}$ does not improve biologic outcomes . Thus, a mandible of $10 \mathrm{~mm}$ height, or inferior-to-superior dimension, is sufficient for an IRO. When four implants of $10 \mathrm{~mm}$ cannot be placed in a severely resorbed mandible, additional implants of shorter dimension may be considered. For example, in an $8 \mathrm{~mm}$ mandible, the use of $8 \mathrm{~mm}$ or $9 \mathrm{~mm}$ implants might be considered if additional implants are included.

\section{Fact 2}

Interocclusal (restorative) dimension measured from ridge crest to occlusal plane must be $\geq 10 \mathrm{~mm}$ (Fig. 2).

This concept of restorative dimension was initially addressed by Phillips and Wong ${ }^{10}$ and reiterated by Lee and Agar; ${ }^{11}$ however, there is little data in support of this inferior-superior dimension for planning of a mandibular IRO. Practically, the restorative dimension for any implant prosthesis includes four key components, each with its own minimum dimension. They are: (1) the transmucosal dimension (biologic width) of approximately $2 \mathrm{~mm}$, (2) a supramucosal abutment height ( $0 \mathrm{~mm}$ to $2 \mathrm{~mm}$ ) that permits hygiene, (3) a framework or attachment height between 3 and $5 \mathrm{~mm}$, and (4) acrylic veneer thickness greater than $2 \mathrm{~mm}$. It must also be acknowledged that the replacement mandibular teeth should accommodate their full contours. The average height of mandibular anterior teeth is approximately $10 \mathrm{~mm}$. A minimum $10 \mathrm{~mm}$ of restorative space places average-size mandibular prosthetic teeth precisely at the soft-tissue crest with only a minimal dimension for the prosthetic components.

It becomes evident that the planning of an implantsupported or implant-retained prosthesis for the edentulous mandible begins with defining a superior-inferior reference, namely, the occlusal plane. Space accommodation for the dimension and location of teeth, frameworks, attachments, retaining abutments (balls, bars, etc), and biologic width will direct planning of implant position. Finally, the location of the osseous crest in relationship to the planned implant position dictates the extent of the alveolectomy required.

\section{Fact 3}

Anterior/posterior distribution of implants must be at least $10 \mathrm{~mm}$ (Fig. 3).

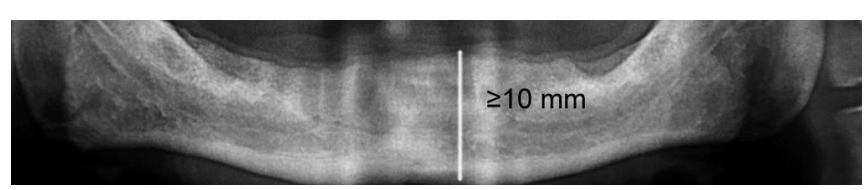

Fig. 1: Inferior/superior dimension of the mandible must be $\geq 10 \mathrm{~mm}$

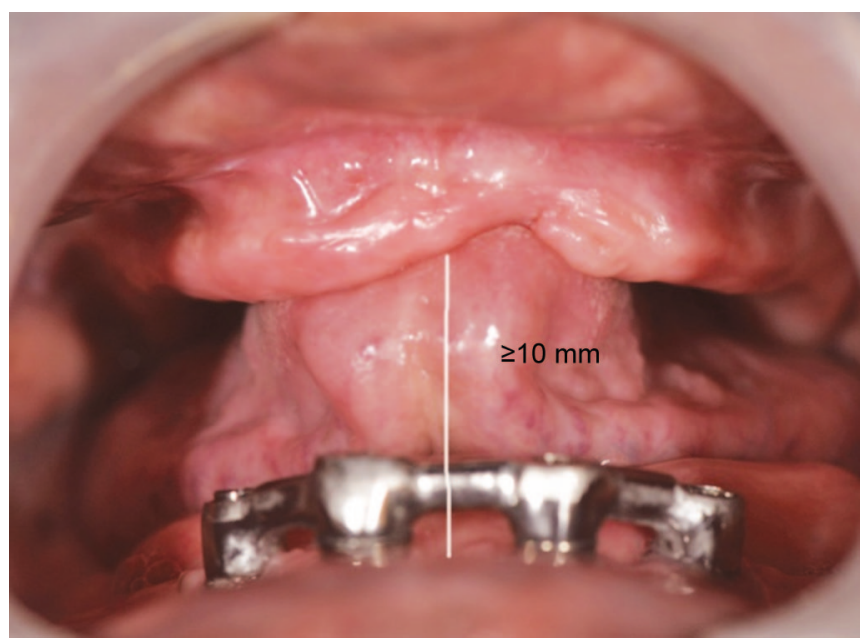

Fig. 2: Interocclusal (restorative) dimension measured from ridge crest to occlusal plane must be $\geq 10 \mathrm{~mm}$

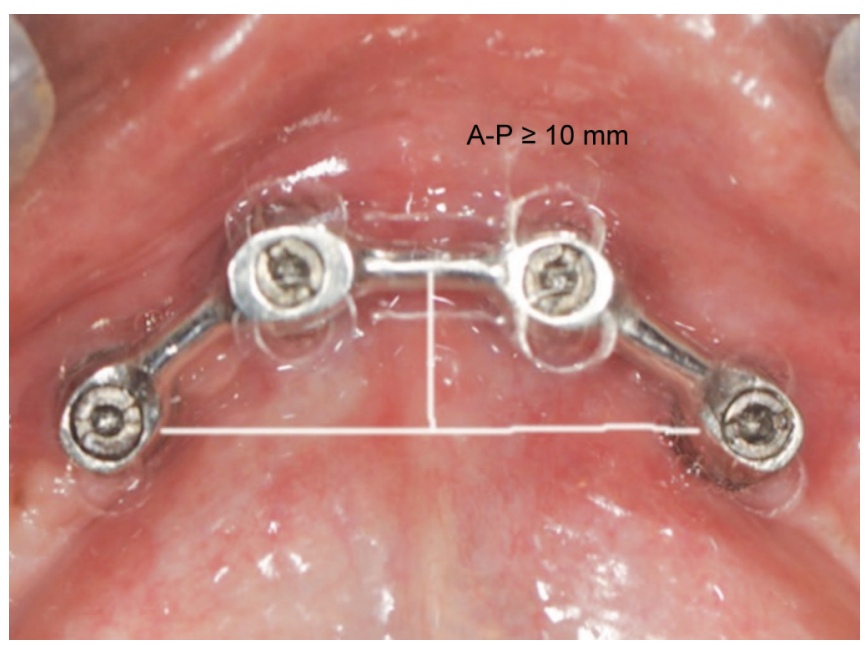

Fig. 3: Anterior/posterior distribution of implants must be at least $10 \mathrm{~mm}$

The implants must be able to support functional loads at the posterior occlusal contacts via the cantilever. These loads, however, are magnified within the framework and components, and potentially at the implant/bone interface. In the early conceptualization of this therapy, the anteriorposterior distribution of dental implants was very important factor for the complications in the cantilevered prosthesis. Thus a maximum distribution of implants was recommended. This anterior-posterior distribution of implants is referred to as the 'A-P spread.' Clinicians were quick to point out that there were anatomic constraints for implant placement in the parasymphyseal mandible. Compared to curved or V-shaped mandibles, square-shaped mandibles often provide little anterior-posterior dimension anterior to the inferior alveolar 
nerve. Additionally, anatomic variations in the inferior alveolar nerve (e.g. anterior loop) are not uncommon ${ }^{12}$ and can reduce the available A-P spread.

Any discussion of cantilever length requires that: (1) the position of the distal-most implant is anticipated; and (2) the number of teeth to be provided distal to that implant be defined. For the purposes of establishing a concept that meets the needs of most patients, the goal is to have the distal implant in the distal-most location that does not impose on the inferior alveolar nerve, which is generally located in the canine or first premolar region. Further, distal inclination of the posterior implants may place the prosthetic interface even more distal in the first premolar region. The all-on-four concept generally requires that posterior teeth supported by a cantilever. Efforts to reduce or eliminate the cantilever by distal orientation of terminal implants are advocated. ${ }^{13}$

The geometric distribution of the implant-abutment and the abutment-prosthesis interfaces remain the significant features of IRO therapy that can be clinically managed to reduce complications.

\section{CONCLUSION}

The use of over dentures supported by implants or natural teeth was an efficacious modality for providing an improved chewing function for the completely edentulous patients. In our study certain facts are highlighted which may be very important in fabrication for successful diagnosis and treatment planning.

\section{REFERENCES}

1. van Steenberghe D, Lekholm U, Bolender C, Folmer T, Henry P, Herrmann I, Higuchi K, Laney W, Linden U, Astrand P. Applicability of osseointegrated oral implants in the rehabilitation of partial edentulism: a prospective multicenter study on 558 fixtures. Int J Oral Maxillofac Implants 1990 Fall;5(3):272-281.

2. Ekelund JA, Lindquist LW, Carlsson GE, Jemt T. Implant treatment in the edentulous mandible: a prospective study on Brånemark system implants over more than 20 years. Int J Prosthodont 2003 Nov-Dec;16(6):602-608.
3. Bryant SR, MacDonald-Jankowski D, Kim K. Does the type of implant prosthesis affect outcomes for the completely edentulous arch? Int J Oral Maxillofac Implants 2007;22Suppl:117-139.

4. Meijer HJ, Raghoebar GM, Batenburg RH, Visser A, Vissink A. Mandibular overdentures supported by two or four endosseous implants: a 10-year clinical trial. Clin Oral Implants Res 2009 Jul;20(7):722-728. doi: 10.1111/j.1600-0501.2009.01710.x. Epub 2009 Mar 27.

5. Cooper LF, Moriarty JD, Guckes AD, Klee LB, Smith RG, Almgren C, Felton DA. Five-year prospective evaluation of mandibular overdentures retained by two microthreaded, Tioblast nonsplinted implants and retentive ball anchors. Int J Oral Maxillofac Implants 2008 Jul-Aug;23(4):696-704.

6. Brånemark PI, Svensson B, van Steenberghe D. Ten-year survival rates of fixed prostheses on four or six implants ad modum Brånemark in full edentulism. Clin Oral Implants Res 1995 Dec,6(4):227-231.

7. Eliasson A. On the role of number of fixtures, surgical technique and timing of loading. Swed Dent J Suppl 2008;(197):3-95.

8. Sertgöz A. Finite element analysis study of the effect of superstructure material on stress distribution in an implantsupported fixed prosthesis. Int J Prosthodont 1997 Jan-Feb; 10(1):19-27.

9. Vercruyssen M, Marcelis K, Coucke W, et al. Long-term, retrospective evaluation (implant and patient centered outcome) of the two implant supported overdenture in the mandible Part1; survival rate. Clin Oral Implants Res 2010;21(4):357-365.

10. Phillips K, Wong KM. Vertical space requirement for the fixeddetachable, implant-supported prosthesis. Compend Contin Educ Dent 2002;23(8):750-756.

11. Lee CK, Agar JR. Surgical and prosthetic planning for a twoimplant-retained mandibular overdenture: a clinical report. J Prosthet Dent 2006 Feb;95(2):102-105.

12. Greenstein G, Tarnow D. The mental foramen and nerve: clinical and anatomical factors related to dental implant placement: a literature review. J Periodontol 2006;12:1933-1943.

13. Malo P, de Araújo Nobre M, Lopes A, Moss SM, Molina GJ. A longitudinal study of the survival of All-on-4 implants in the mandible with up to 10 years of follow-up. J Am Dent Assoc 2011 Mar;142(3):310-320.

\section{ABOUT THE AUTHOR}

\section{Farhan Durrani}

Associate Professor, Department of Periodontics, Banaras Hindu University, Varanasi, Uttar Pradesh, India, Phone: 09335873366 e-mail: docfarhan@rediffmail.com 